\title{
Methodological and organizational problems of professional risk management in construction
}

\author{
Evgeny Sugak ${ }^{1 *}$ \\ ${ }^{1}$ Moscow State University of Civil Engineering, Yaroslavskoe shosse, 26, Moscow, 129337, Russia
}

\begin{abstract}
The construction industry is one of the most traumatic industries, therefore, the improvement of the occupational safety and health management system (OSH) in construction is an urgent problem. The Russian government has set the task of reforming the national OSH on the basis of professional risk management, which will allow switching from the practice of responding to the incidents that have already occurred to preventive detection and elimination of potential threats. This article discusses the issues of the objective nature of occupational risks, methods for assessing the probability and severity of damage from risk events, and also provides recommendations on the content of the functional responsibilities of officials of the construction organization.
\end{abstract}

\section{Introduction}

This research is aimed at studying the methodological and organizational problems of professional risk management in construction. In many countries, including Russia, construction is one of the most traumatic industry of all types. Both the frequency of the origin of accidents and the severity of the injuries caused industrial accidents at the construction site outstrips other sectors of the national economy. The objective reality is that the nonstationary nature of jobs, a significant proportion of manual labour, the severity and intensity of labour processes, significant fluctuations in natural climatic factors have been and will negatively affect the health of workers, reflect on the productivity and quality of their work, on the economic indicators of the construction firm.

An alternative to the current adverse situation with the safe performance of numerous construction processes is the creation and functioning of a modern OSH management system that, with the help of new methods and organizational innovations, can mitigate the negative effect of the labour conditions of builders, reduce the level of potential hazards and harmfulness.

Industrial injuries, occupational and production-related diseases are a serious social and economic problem for each state. Damage to health, which the able-bodied, and therefore the most active part of the population, receives in the process of production negatively affects the preservation of the country's human resources, reduces the average life expectancy, and worsens the demographic situation. Therefore, the Government of the Russian Federation, developing medium-term and long-term plans for the country's social

\footnotetext{
Corresponding author: SugakEB@mgsu.ru
} 
and economic development, attaches great importance to the implementation of measures to improve working conditions, preserve health and labour activity of workers, and improve the social protection of workers [1].

In October 2011, the Government of the Russian Federation adopted a decree on measures to improve working conditions, preserve the lives and health of workers. The document noted that the country recorded a high level of industrial injuries and occupational diseases, several times higher than that of developed countries, due to adverse working conditions, the fund of working hours is seriously lost. The government estimated the country's total economic losses from occupational diseases and injuries at $4.3 \%$ of GDP or 1.94 trillion rubles, which was somewhat higher than the costs of the Russian Federation for defense in those years [2].

The Resolution stressed that the main problem of the negative situation with labour protection activities is the ineffective system of labour protection management, which was established in the Soviet era, but which to a large extent continues to function. In this regard, the Government of the Russian Federation has embarked on implementing measures to transition from the compensation model of labour safety to a modern model based on the management of professional risks. The new model of labour protection should allow to avoid the practice of responding to the already occurred facts of injuries or various diseases to the mechanism for developing and implementing preventive measures to prevent accidents, and to preserve the health of personnel.

In the reform of the national OSH management system, the practical results demonstrated by developed countries in the field of labour safety modernization, which they started to carry out in the 1970 s, play a significant role. The resulting positive trends in reducing overall labour losses, a significant reduction in the incidence of occupational injuries and occupational diseases, are associated with the creation and implementation of a new model of occupational safety in practice, on the basis of which a modern management system was formed, known as the "Management system for production safety and health (MS PSH)" [3, 4]. For example, at the enterprises of Germany in the period from 1968 to 1983, the number and death of other incidents and diseases decreased significantly, from 4200 to 1521 , respectively [5].

\section{Methodology}

In accordance with the instructions of the Government of the Russian Federation, work is being carried out in the Russian Federation to implement the provisions of the modern model of the industrial safety and health system.

\subsection{National standards of OSH management}

In particular, the national standard GOST 12.0.230-2007 "Occupational health and safety management systems was developed and put into operation. General requirements ", the text of which is harmonized with the normative document of the International Labour Organization (ILO OSH - 2001). Soon the standard GOST R 54934 - 2012 "Occupational Health and Safety Management Systems" was developed and adopted, the content of which is identical to the international standard OHSAS 18001: 2007 [7, 8]. With varying degrees of success, state programs are being implemented to certify work places for working conditions and for a special assessment of workplaces for working conditions.

However, in practice, despite the existence of basic regulatory documents, the OSH management system at the enterprise is being reformed slowly, the methods of the traditional model of labour protection, based not on creating a safe production environment, 
but on supervising and monitoring personnel compliance with labour protection requirements, continue to dominate. Implementation of the provisions of national standards encounters a number of obstacles, one of which is the lack of theoretical training of managers and specialists on the methodological and organizational content of the modern model of professional risk management.

The activity of any construction organization is fraught with risk, therefore risk management, or risk management, should be used in all business processes. Thus, procedures for assessing occupational risks are recommended as an initial step in the formation of approaches to managing the safety and health of workers, as well as the construction of a system of labour protection in enterprises. Since 1989, when the European Union adopted the framework Directive on the introduction of measures to promote improvements in the safety and health of workers at work, risk assessment has become the cornerstone of the European approach to occupational safety and health. In 2011, the Federal Law of the Russian Federation introduced amendments and additions to Article 209 of the Labour Code of the Russian Federation concerning the definition of the concepts "professional risk" and "management of occupational risks", and also introduced the national standard GOST R 12.0.010-2009 " SSBT. Occupational safety management systems. Identification of hazards and risk assessment "[9].

\subsection{Factors of the risk management system}

The content of the new approach to ensuring occupational safety through the management of professional risks consists in the fact that the subject of practical actions should be both the occurred facts of damage to health, and potential, not yet manifested industrial threats that are in an implicit, hidden form and which must be recognized, evaluated and minimized (or eliminated) in advance. Practice shows that production hazards and harmful, consisting in an implicit form, constitute a more significant array of threats than the incidents that have occurred, and their recognition, evaluation and elimination have a more significant preventive effect than responding to already-occurred facts of health damage. In addition, the direct control of the parameters of the construction process, carried out on its way in a constant mode, is more effective than monitoring the results of the same process, performed only at the last stage of the event.

From the point of view of labour protection, this means certain advantages in the formation of safe working conditions possessed by procedures for the management of occupational risks that are carried out on a continuous basis, before investigation procedures conducted only after a dangerous incident occurred. Another positive factor of the risk management system is that it makes it possible to predict the results of the process, namely, to presume with a sufficient degree of probability the dynamics of improvement or deterioration of labour safety [3].

\section{Results and discussion}

The creation and introduction of a professional risk management system into the practice of a construction organization is due to the implementation of organizational and methodological decisions, the main ones of which are the following. 


\subsection{Professional risks and their evaluation}

Risks are created by the dangers and harmfulness of the working environment, as well as by the severity and intensity of the workload of the personnel. Previously, it was believed that it was necessary to strive to create absolute security, to prevent any negative manifestations of the production environment, but from the concept of "zero risk" had to be abandoned, because all spheres of life, especially in the field of material production, are accompanied by risky situations, which cannot be avoided. Today, in practice, the concept of "acceptable risk" is used. risk, the level of which is accepted by acceptable state instances, the production community, public organizations and directly by working collectives.

Risks are an objective phenomenon in the activity of the construction organization, they accompany all and all directions of its activity. Despite the fact that a number of risk parameters may depend on ambiguous actions of personnel or on subjective management decisions, the objective nature of its manifestation remains unchanged. Risk management helps to get out of the uncertainty zone into a situation with more or less predictable results.

Two important points are characteristic of the professional risk management system. First, management activities are a cyclic sequence of performing interrelated practical actions, known as the "Deming-Shuhart cycle" or as a PDCA cycle (Fig. 1). The content of the cycle includes a set of procedures divided into several stages: Planning - Doing Studying the result - Action (act). After the completion of the work of the last stage, a new cycle of the same practical actions should begin at the same workplaces, but with new goals and tasks to reduce risks. And, secondly, the implementation of the same cyclic procedures realizes the so-called "process approach", which is carried out continuously, in solving problems, and which creates conditions for the permanent improvement of the OSH management system.

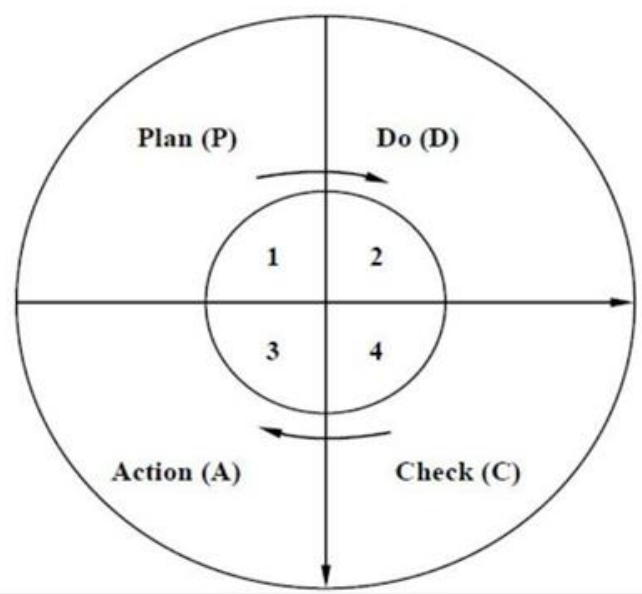

Fig. 1. Scheme of the Deming-Schuhart cyclic process (PDCA cycle).

The conception of risk means a combination of two factors - the probability (frequency) of the origin of damage and the severity of this damage. The probabilistic nature of the risk is associated with the potential manifestation of an industrial hazard and harm and with the uncertain nature of their possible occurrence. In other words, a risky event may or may not occur. The degree of this probability is determined by the action of both objective and subjective factors, but the probabilistic nature of risk is a constant characteristic of it.

In case of the probability of material or other damage is higher, the expected losses and the risk is more significant. At the same time, risks can be the same in those cases when 
situations arise, for example, with the maximum probability of the origin of the damage and the minimum indicators of its severity. Or vice versa, in an environment of low probability of loss with simultaneous expectation of significant damage.

It is possible to control only those processes that have measurable or estimated parameters. In the field of labour protection, such hazards are taken as production hazards and hazards, expressed through quantitative or qualitative indicators of occupational risk. Risk management means the recognition and analysis of risks, the development and implementation of management decisions to reduce the probability of adverse situations, as well as to reduce possible material or other losses.

To assess the probability and severity of the manifestation of occupational risk, apply various methods that use quantitative or qualitative parameters. For example, a direct evaluation is performed according to statistical data on traumatism and occupational diseases using the frequency, severity, death and disability rates, injury rate index and other data. The reliability of the manifestation of danger and the onset of damage to a decisive extent will depend on the amount of available statistical information. With a quantitative inadequacy of objective data on incidents, the risk assessment may reflect a non-sustainable phenomenon, but a random process. Therefore, it is advisable to use statistical data for large corporations or entire branches of the economy, which in their activity accumulate significant amounts of relevant information.

For a separate enterprise, for the scale "workplace - small production" it is preferable to apply a qualitative risk assessment in the format "more - less" based on the opinion of experts, which most often will be the direct executives of the construction organization of the middle level. Considering their theoretical preparation, the expert evaluation methodology should be simple in understanding and in execution and, at the same time, reflect the objective nature of the risk. For this, use the method of verbal functions, which consists in that each level of qualitative risk assessment is given a brief description of a potentially dangerous situation. For example, when dividing the probability of damage and the extent of damage by three steps, a verbal description of the situation can be presented in the form of the contents of Table 1.

Table 1. Three-level scale of probability of damage occurrence and severity of damage.

\begin{tabular}{|c|l|l|}
\hline $\begin{array}{c}\text { Probability/ } \\
\text { Severity of } \\
\text { damage }\end{array}$ & \multicolumn{1}{c|}{$\begin{array}{c}\text { Verbal description } \\
\text { of probability of damage }\end{array}$} & \multicolumn{1}{c|}{$\begin{array}{c}\text { Verbal description } \\
\text { of severity of damage }\end{array}$} \\
\hline Low / & $\begin{array}{l}\text { The danger or its manifestations, } \\
\text { which can cause some damage, should } \\
\text { not arise during the entire period of } \\
\text { the employee's professional activity. }\end{array}$ & $\begin{array}{l}\text { The injured worker is not required to } \\
\text { provide medical assistance; in the } \\
\text { worst case, a 3-day absence from } \\
\text { work. }\end{array}$ \\
\hline $\begin{array}{c}\text { Average / } \\
\text { Average }\end{array}$ & $\begin{array}{l}\text { Danger or its manifestations, which } \\
\text { can cause some damage, arise only in } \\
\text { certain periods of professional activity } \\
\text { of the employee. }\end{array}$ & $\begin{array}{l}\text { The injured worker is taken to the } \\
\text { health care organization or is required } \\
\text { to vit her; absence at work for up to } \\
\text { days; development of chronic } \\
\text { disease. }\end{array}$ \\
\hline
\end{tabular}




\begin{tabular}{|l|l|l|}
\hline & & $\begin{array}{l}\text { Accident causes serious (untreatable) } \\
\text { damage to health; treatment in hospital }\end{array}$ \\
High / & $\begin{array}{l}\text { Danger or its manifestations, which } \\
\text { can cause some damage, arise } \\
\text { Heavy }\end{array}$ & $\begin{array}{l}\text { constantly during the whole absence at work for more } \\
\text { professional activity of the employee. } \\
\text { than 30 days; persistent disability or } \\
\text { death. }\end{array}$
\end{tabular}

The implementation of the professional risk management system requires that the assessment of occupational risk is carried out precisely by measurable quantitative parameters, which would make it possible to compare them with the level of hazards whose quantitative characteristics are recognized as acceptable. In developed countries, a method based on the probability-damage matrix is often used for direct quantitative risk assessment [10]. The content of the method is that the expert or experts for each situation describe its content and rank the probability of damage, for example, on a three-level scale. Further, each weight of probability and severity of damage is assigned a weighting factor. In this case, the absolute value of the coefficients may be different, only the relative relationship between the values of the weight coefficients has a significant value [9].

The weight coefficients of damage severity and probability of damage occurrence for each level are proposed to be established, for example, by values of 0.3 , respectively; 0.7 and 1.0. At the intersection of a particular column and line is the desired relative risk, it is obtained by multiplying the weighting coefficients of the severity of damage and the probability of the event and expresses the quantitative interpretation of the value of occupational risk (Table 2).

Table 2. The quantification of the value of occupational risk.

\begin{tabular}{|c|c|c|c|}
\hline \multirow{2}{*}{$\begin{array}{c}\text { Severity of damage and } \\
\text { the value of the } \\
\text { weighting factor }\end{array}$} & \multicolumn{3}{|c|}{$\begin{array}{c}\text { The value of the risk with probability (frequency) and } \\
\text { weight coefficient of emergence of the damage }\end{array}$} \\
\cline { 2 - 4 } & Low -0.3 & Average -0.7 & High -1.0 \\
\hline Light weight -0.3 & 0.1 & 0.2 & 0.3 \\
\hline Average -0.7 & 0.2 & 0.5 & 0.7 \\
\hline Heavy - 1.0 & 0.3 & 0.7 & 1.0 \\
\hline
\end{tabular}

\subsection{Characteristics of the origin of accidents}

One of the important features of the reformed model of labour protection is a change in the notion of the nature of the origin of accidents. In the framework of traditional approaches, the causes of the occurrence of an industrial incident are most often recognized as subjective reasons caused by violations of the requirements of labour protection by a worker. At the level of the executor, such a version has the right to exist, but for the production manager it does not allow for the recording and management of professional risks, and effectively carry out preventive measures.

Today, professional risks are primarily associated with objective reasons, namely, the presence at each workplace of a certain level of pro-industrial hazards and hazards. When dangers and harmfulness manifest themselves, they cause the employee damage to one or another degree of severity, including with disability. The more hazards and hazards are in the production, the more incidents and professional diseases usually occur there [11]. 
The manifestation of operational hazards and hazards that are in an explicit and implicit condition, and the resulting damage to human health, illustrates the Heinrich's Injury Pyramid [12]. The levels of the pyramid reflect the severity of the negative impact of the production environment - from a minor incidence to a lethal outcome (Fig. 2).

Heinrich established that between a number of dangerous production factors and a degree of severity from their manifestation there is a certain stable mathematical dependence. For one serious injury or death in the workplace there are 29 - 30 accidents with less severe consequences and with disability, and 300 - 330 minor incidents that can pass almost unnoticed [12].

The revealed numerical dependence between the severity of the accident and the number of dangerous production factors is, first, another confirmation of the objective nature of the origin of occupational traumatism and, secondly, an analytically established ratio allows us to formulate the main content and essence of the methodology for managing professional risks. From the analysis of the Heinrich's Injury Pyramid it follows that the concentration of efforts of labour safety specialists to implement measures to reduce, for example, the number of registered accidents or the number of fatalities, do not have a significant effect, because they do not expose the essential causes of the accident. Only a reduction in the base of the Heinrich's Injury Pyramid, i.e. reducing the number of hazards and hazards, allows you to reduce the number of incidents, respectively, for each severity of damage.

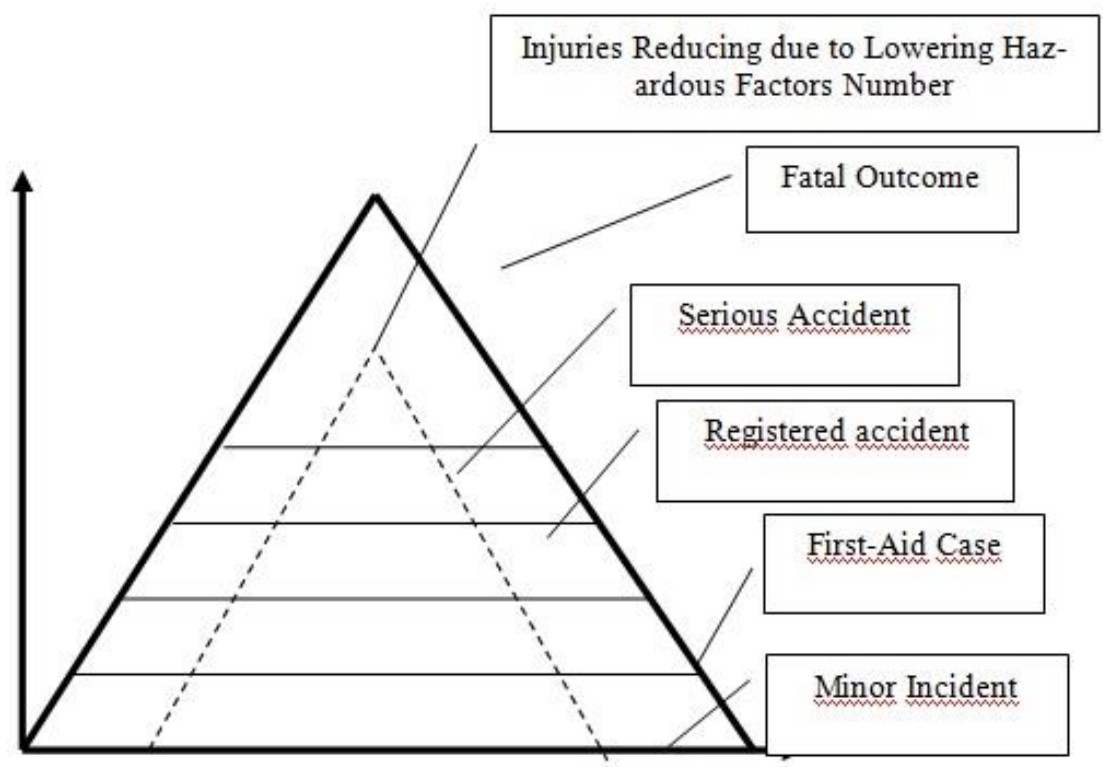

Hazards Number

Fig. 2. The Heinrich's Injury Pyramid (1931).

The recognizing the objective nature of the origin of injuries and occupational diseases implies that preventive measures should also have objective content aimed at reducing the level of production hazards and hazards. Namely, carrying out work to change the process, use less hazardous or safe substances and mechanisms, use effective protective systems and devices that combine to create an objectively safe production environment. It is important to emphasize that the formation of an objective safety factor in production should be 
implemented exclusively by technical and organizational methods without the use of "labour heroism of personnel".

\section{Conclusions}

The implementation of methodological and organizational procedures, which are characterized as "professional risk management", are the basic component for the formation in the construction organization of a modern OSH management system, which ideally should be adapted to the systems of quality management and environmental safety and is integrated into the general management system of the construction organization. Negative consequences of adverse working conditions appear on the construction site, however, the safety of technological processes, like other aspects of production, are laid down in the decisions of the employer and other officials. Identifying and assessing the level of potential threats and implementing optimal technical solutions to minimize them will create an objectively safe production environment.

\section{References}

1. Concept of the demographic policy of the Russian Federation until 2025. Decree of the President of the Russian Federation from 9 October 2007, No. 1351. (Rus)

2. Golikova T.A. On measures aimed at improving working conditions, preserving life and health of employees. Report on the meeting of the Government of the Russian Federation on October 27, 2011. Occupational safety and health in construction. - No. 1. Pp.7-11. (2012)

3. Fedorets A.G. Management of industrial safety and risk assessment. Moscow, "IBT", 152 p. (2012)

4. Litvinov R.A. Formation of OSH management systems. Trends in international level. Occupational safety and health in construction. No. 4, Pp.12-18. (2013)

5. Sugak E.B. The nature of occupational injuries in the aspect of managing pro-fessregional risks. Life safety. No. 7, Pp.3-7. (2015)

6. Alexandrova E.V. Trick or Treat. Businessman-Business Guide. Protection of labor. No. 204 / B Pp. 30-31. (2006)

7. GOST 12.0.230 - 2007 "SSBT. Occupational safety management systems. General regulations". Moscow, Standartinform, 16 p. (2007)

8. GOST R 54934 - 2012 "Occupational safety and health management systems". Moscow, Standartinform, 27 p. (2012)

9. GOST R 12.0.010-2009 "SSBT. Occupational safety management systems. Definition hazards and risk assessment". Moscow, Standartinform, 20 p. (2011)

10. Fedorets A.G. Methodical bases of quantitative estimation of production - Energy security in documents and facts. No. 2, Pp. 10-16 (2008)

11. Sugak E.B. On the modern model of labor protection. Sb. Theses of Int. scientific conference "Integration, partnership and innovations in building science and education". Moscow, MSUCE. p.185-186. (2013)

12. H.W. Heinrich. Industrial accident prevention; a scientific approach. New York, McGraw-Hill, 480p. (1959)

13. Sugak E.B. On some of the official duties of security specialists Labor in Germany. Man and work. No. 10. Pp.48-51. (2013) 